\title{
Risk society and COVID-19
}

\author{
Fardin Mansouri ${ }^{1}$ (D) Fatemeh Sefidgarbaei $^{2}$ (D)
}

Received: 15 December 2020 / Accepted: 5 January 2021 / Published online: 19 January 2021

(C) The Canadian Public Health Association 2021

\section{Dear Editor:}

Today, social risks have become part of our daily lives as human beings. The German sociologist Ulrich Beck defined them as the systematic way of dealing with the perils and insecurities resulting from modernization. He attributed this issue to a broad change, which he called "reflexive modernization", where the unintended and unpredictable impacts of modern life on modernity take place (Beck 2000). In the risk society, the people's concerns are shifted from natural disasters to the perils resulting from human activities, which are often global and widespread (Turner 2002).

In sum, risk society does not merely arise from the reality that daily life has generally become more dangerous; the problem is more about fading the borders of uncontrollable risks (Ritzer 2004). In the context of pandemic diseases, and in particular, COVID-19, which can be defined as a disease of the risk society, this uncontrollable border fading is noticeably visible - from all developing to developed countries.

Facing COVID-19 is taking place at three dimensions: distance, time, and society. The distance aspect means that the disease is non-localized so that it has distanced from the statenation level and has spread to the world community. On the distance side, we find ourselves encountering a peril that has no boundaries. In fact, coronavirus is the real phenomenon of globalization, even though we must keep in mind that we must see global threats and opportunities together. Undoubtedly, living in the post-COVID-19 world requires a rethinking of the intelligent system for all nations. From this perspective, the current

Fatemeh Sefidgarbaei

fateme.sefidgar.baei@gmail.com

Fardin Mansouri

fardinmansouri@gmail.com

1 Department of Sociology, Faculty of Humanity and Social Sciences, Kharazmi University, Tehran, Iran

2 Department of Social Sciences, Faculty of Letters and Human Sciences, Shahid Beheshti University, Tehran, Iran outbreak should be considered an opportunity to make significant changes in future life. It could be argued that coronavirus is the invasion of reality and kind of a slap in the face of the individualistic world, requiring social solidarity, empathy, cooperation, and moralization.

The time aspect points out the critical periods of the disease and its different consequences, which should be considered separately. On the time side, the long incubation period of the disease, as well as the prolongation of the anti-COVID-19 vaccine production and the spread control process, have become a global problem. These issues have long-term consequences in various social, economic, and political dimensions for all governments worldwide, demanding extensive and expansive efforts to deal with them.

Finally, the outbreak of coronavirus should be considered one of the most important social events in the twenty-first century. The most significant inherent characteristics of all pandemic crises, including COVID-19, are the emergence of social stress and anxiety due to the unfamiliarity and ambiguity of the phenomenon, disruption in institutions' order and function, and reduced social interactions.

Authors' contributions The authors contributed equally.

Data availability Not applicable.

\section{Compliance with ethical standards}

Conflict of interest The authors declare that they have no competing interests.

Ethics approval Not applicable.

Consent to participate Not applicable.

Consent for publication Not applicable.

Code availability Not applicable. 


\section{References}

Beck, U. (2000). Risk society revisited: theory, politics, and research programs. In B. Y. Adam, U. Beck, \& J. van loon (Eds.), The risk society and beyond: critical issues for social theory. London: Sage.

Ritzer, G. (Ed.). (2004). Encyclopedia of social theory. London: Sage Publications.
Turner, B. S. (2002). Orientalism, postmodernism, and globalism. London: Routledge.

Publisher's note Springer Nature remains neutral with regard to jurisdictional claims in published maps and institutional affiliations. 